\title{
GÊNEROS TEXTUAIS: UMA INTERVENÇÃO PEDAGÓGICA
}

\author{
Cibele Avellar de Souza ${ }^{1}$ \\ Bárbara Guardiano de Castro Moreira ${ }^{2}$ \\ Michelle Priscila dos Santos ${ }^{3}$ \\ Vera Lúcia Catoto Dias ${ }^{4}$ \\ Anamaria da Silva Martin Gascón Oliveira ${ }^{5}$
}

Resumo: Este trabalho é continuidade de pesquisa do Programa Institucional de Bolsa de Iniciação à Docência, PIBID, convênio firmado entre universidade comunitária e escola pública, para formação inicial de professores na educação básica. O objetivo do trabalho é investigar o processo de alfabetização, construção da língua escrita, tendo como suporte os gêneros textuais. A pesquisa em educação do tipo estudo de caso etnográfico (ANDRÉ, 2005), no período de 2015-2016, realizada pela observação participante de bolsistas PIBID, em sala do $4^{\circ}$ ano do Ensino Fundamental I, em uma escola estadual, localizada no município de São José dos Campos, SP. A metodologia centrou-se inicialmente em pesquisa bibliográfica fundamentada em: Bezerra (2002), Marcuschi (2002), e Bakhtin (2003, p. 271), dentre outros, seguida de pesquisa de campo. Os resultados apontaram para as contribuições dos gêneros textuais na alfabetização ao longo do processo.

Palavras-chave: PIBID, gêneros textuais, alfabetização, intervenção pedagógica.

\footnotetext{
${ }^{1}$ Pedagogia/Univap, Brasil. E-mail: cibele.avellar@gmail.com.

2 Pedagogia/Univap, Brasil. E-mail: barbarasjc@yahoo.com.br.

3 Pedagogia/Univap, Brasil. E-mail: mihprisantos@gmail.com.

4 Pedagogia/Faculdade de Educação e Artes/Univap, Brasil. E-mail: vcatoto@univap.br.

${ }^{5}$ Pedagogia/Faculdade de Educação e Artes/Univap, Brasil. E-mail: gascon@univap.br.
} 